\title{
O PROCESSO DE GESTÃO EM UMA EMPRESA FAMILIAR
}

\section{THE MANAGEMENT PROCESS IN A FAMILY COMPANY}

Recebido em 12.12.2019 Aprovado em 19.12.2019

Avaliado pelo sistema double blind review DOI: https://doi.org/10.32888/cge.v7i3.39890

\section{Ana Carla Teixeira dos Santos}

ana.santos7@,ufv.br

Universidade Federal de Viçosa, Campus Rio Paranaíba - Rio Paranaíba/Minas Gerais, Brasil

\author{
Áurea Lúcia Silva Andrade \\ aurea.andrade@ufv.br \\ Universidade Federal de Viçosa, Campus Rio Paranaíba - Rio Paranaíba/Minas Gerais, Brasil
}

\section{Resumo}

No Brasil a maioria dos empreendimentos são familiares e não possuem gestão profissional. Isto explica, em partes, o insucesso destas empresas, o que torna relevante pesquisas sobre o processo de gestão de empresas familiares. A presente pesquisa pode ser classificada como qualitativa descritiva e possui como método de abordagem um estudo de caso na Empresa Savana Serviços, localizada na cidade de Araxá - MG, e tem como objetivo geral investigar como se dá o processo de gestão de uma empresa familiar. Por meio de análise de conteúdo temática as entrevistas foram analisadas e os dados discutidos à luz do referencial teórico. A pesquisa comprovou o papel do fundador na evolução da Savana Serviços. A gestão da empresa é compartilhada entre pai, filha e genro. A empresa não possui um organograma formal, mas há uma divisão informal de responsabilidades. Observou-se que a Empresa Savana cresceu conforme os membros da família perceberam oportunidades e ajustaram a empresa para transformar estas oportunidades em negócios. A experiência do fundador é valorizada pelos membros familiares presentes na gestão e a vivência no dia a dia da empresa é fator importante na gestão da empresa Savana.

Palavras-chave: Empresa Familiar. Gestão. Evolução.

\begin{abstract}
In Brazil, most companies are family owned and do not have professional management. This partially explains the lack of knowledge about these companies or research into the family business management process becomes relevant. This research can be used as a descriptive qualitative and has as a method of approach a case study in the Company Savana Serviços, located in the city of Araxá MG, and aims to investigate how the family business management process. Through thematic content analysis, the interviews were analyzed and the data discussed in the light of the theoretical framework. Work or research proven by the founder of Savana Services. Company management is shared between father, daughter and son-in-law. A company does not have a formal organization chart, but there is an informal division of obligations. Note that Savannah Company has grown as family members perceive opportunities and has adjusted the company to turn those opportunities into businesses. The founder's experience is valued by family members in management and the company's daily experience is an important factor in Savana's management.
\end{abstract}

Keywords: Family Companies. Management. Evolution. 


\section{Introdução}

A dinâmica e o crescimento da economia dos países em desenvolvimento dependem, em grande parte, das empresas familiares. Os empreendimentos familiares geram trabalho e renda para a população economicamente ativa e têm o potencial de melhorar o posicionamento mais estratégico dos países emergentes no cenário econômico mundial.

Dados do IBGE e do SEBRAE mostram que 90\% das empresas no Brasil ainda são familiares. Estas empresas representam cerca de $65 \%$ do PIB e empregam $75 \%$ da força de trabalho do país (SEBRAE, 2019). Ainda que os dados do IBGE e SEBRAE reforçam a importância estratégica das empresas familiares e que estas podem ser consideradas propulsoras da economia nacional há dados que apontam o alto índice de insucesso das empresas familiares. A cada 100 empresas cerca de $70 \%$ não passam da geração do fundador e apenas 5\% conseguem chegar à terceira geração, conforme dados do SEBRAE (2019).

Bernhoeft (2005) aponta a falta de boa gestão como um fator que explica o índice de insucesso das empresas familiares. Segundo o referido autor, muitas empresas familiares ainda gastam tempo, energia e dinheiro para conseguir clientes e esquecem de investir na gestão das empresas.

Os empreendimentos geridos por uma família, que também faz parte da fundação do negócio, enfrentam problemas complexos e diversos com natureza específica por causa da origem do negócio e dinâmica da empresa ao longo de sua história. Diante da percepção da importância econômica e social das empresas familiares e da complexidade do processo de gestão destas empresas propõe-se como problema de pesquisa investigar como é a gestão de uma empresa familiar.

Neste sentido, buscou-se, de maneira geral, investigar como se dá o processo de gestão na empresa familiar Savana Serviços, localizada em Araxá, Minas Gerais. De maneira específica, buscou-se identificar a trajetória da empresa familiar analisada e a evolução dos negócios; descrever a trajetória profissional do fundador e membros da família que atuam como gestores na empresa Savana; identificar o processo de tomada de decisão na gestão da empresa Savana.

A Savana Serviços atua no mercado há 22 anos e oferece serviços de madeireira, carvoeira, locação de maquinário, prestação de serviços. Com 53 funcionários fixos, em 2019 a empresa tem a presença de membros de gerações diferentes que atuam diretamente na gestão e na tomada de decisão.

O presente artigo foi dividido em seis partes. Além da apresentação do problema de pesquisa e sua relevância descritos na primeira parte, apresenta-se, na segunda parte, uma revisão bibliográfica para delimitar o referencial teórico no qual a pesquisa está ancorada. Na terceira parte apresentam-se os procedimentos metodológicos adotados para a realização da pesquisa. $\mathrm{Na}$ sequência apresentam-se os resultados e análise da pesquisa. Finalmente, na quinta parte, apresentam-se as considerações finais. Na sexta parte são listadas as referências bibliográficas.

\section{Empresa Familiar: gestão e desafios}

A empresa familiar caracteriza-se como uma forma de organização predominante no Brasil, o que desperta a necessidade de pesquisas sobre esta temática. Além de Paiva et al (2008) que fazem uma análise das publicações sobre empresa familiar, outras pesquisas são realizadas para compreender as especificidades das empresas familiares nos processos de sucessão e governança corporativa (TESTON e FILIPPIM, 2016; MURITIBA et al., 2016), por exemplo. Destaca-se também uma relevante produção na análise do ciclo de vida das empresas familiares como o trabalho de Frezatti et al. (2017).

Um metaestudo publicado por Paiva et al. (2008) apresenta análise de publicações nos eventos da Associação Nacional de Pós-Graduação e Pesquisa em Administração (ANPAD) sobre empresas familiares, entre 1997 e 2007. Os referidos autores analisaram 83 artigos e apontaram que 71,1\% têm base teórico-epistemológica funcionalista e $24 \%$ têm base interpretacionista. Paiva et al. (2008) destacaram de maneira positiva o crescimento da base teórico-epistemológica de base 
interpretacionista, pois indicam investigações que podem contribuir para a compreensão das ações humanas nas empresas familiares. Ainda apontam que trabalhos nesta base suplantam a descrição de causa-efeito funcionalista e proporcionam análises mais profundas e relacionais, presentes na empresa familiar. Os autores citados destacaram também a predominância de estudos teórico-empíricos em temas sobre sucessão, estratégia, modelos de gestão, profissionalização, cultura, aprendizagem, representações sociais, mudança, empreendedorismo e sistemas contábeis. Pode-se afirmar que o trabalho realizado por Paiva et al. (2008) ressalta a importância do tema na agenda da pesquisa nacional.

Teston e Filippim (2016) analisaram os processos de sucessão de empresas familiares de Chapecó, Santa Catarina. Em uma abordagem de caso múltiplo e numa perspectiva qualitativa, os referidos autores (2016, p.540) concluíram que:

[...] a preparação de sucessores se dá por meio de aspectos que se encontram intricados na relação família e empresa: da influência do fundador, dos processos de socialização multigeracional e legitimação, das questões demográficas com os fatores de distintividade na sucessão familiar, do movimento existente entre a aprendizagem e a sucessão aos indícios de uma proposta de sucessão para a empresa familiar.

Muritiba et al. (2016) retratam em um caso real para ensino a sucessão em uma empresa familiar do ramo da educação. A morte repentina do fundador levou os herdeiros a buscar numa consultoria a melhor forma de assumirem a gestão da Faculdade e suas três unidades e implantar a governança corporativa no contexto de uma empresa familiar. O caso retratado por Muritiba et al. (2016) retrata a realidade de muitas empresas familiares que não se preparam para a sucessão e, muitas vezes, enfrentam este processo em função de uma situação inesperada e consequentemente de forma mais traumática.

Frezatti et al. (2017) realizaram pesquisa quantitativa sobre os estágios do ciclo de vida e perfil de 117 empresas familiares brasileiras. A pesquisa baseou-se no modelo F-PEC de Artrachan et al. (2002 apud Frezatti et al., 2017) que analisa as empresas a partir de três dimensões a saber: o poder, a experiência e a cultura. Segundo Frezatti et al. (2017) no nascimento das empresas familiares, o poder e a cultura têm papéis importantes; na maturidade, a experiência e a cultura se destacam; e no rejuvenescimento, o poder e a cultura são mais característicos. A pesquisa contribui para o entendimento dos diferentes elementos da vida organizacional de empresas familiares e pode auxiliar na migração para estágios desejáveis como crescimento ou rejuvenescimento, conforme concluem os autores supracitados.

As inúmeras pesquisas realizadas sobre as empresas familiares reforçam a importância destas empresas para a economia nacional. Neste trabalho, busca-se delimitar a definição de empresa familiar para justificar a relevância deste estudo e delimitar suas possíveis contribuições para o entendimento do processo de gestão de empresas familiares especialmente pelo fato de que a natureza familiar é uma característica que influencia o campo organizacional destas unidades de análise conforme destacam Casillas, Vázquez e Diaz (2007).

A natureza familiar tem efeito sobre estas organizações específicas como pontuam Casillas, Vázquez e Diaz (2007) e o vínculo existente entre os familiares pode ser capaz de gerar vantagem competitiva, uma vez que as relações de confiança e afeição já estarão preestabelecidas, conforme destaca Martins (2001). No entanto, por outro lado, Martins (2001) afirma que as empresas familiares possuem um perfil bem peculiar de organização, pois sofrem impactos diretos no método de administração por parte de seus fundadores e de sua cultura.

A caracterização familiar para as empresas se dá somente na segunda geração de dirigentes (LODI, 1994). Oliveira (2006) caracteriza a empresa familiar como uma empresa cuja propriedade pertença a uma ou mais famílias, independentemente de sua natureza jurídica.

A presença de familiares na empresa gera a origem de conflitos de interesse em função da tridimensionalidade dos sistemas destas organizações, conforme Bornholdt (2005) salienta. Como o referido autor destaca a tridimensionalidade das empresas familiares é construída nos planos família, sociedade e empresa. Bornholdt (2005, p.5) ressalta que o "convívio de diferentes gerações, idades, sexos, papeis e funções proporciona um ambiente potencialmente favorável ao surgimento de atritos, tensões e divergências". Não há, portanto, como negar que as estratégias de políticas e gestão das 
empresas familiares são construídas em torno da influência exercida por um ou mais membros da família proprietária (DAVIS, 2003).

Ciente dos desafios e da necessidade de prosperar, as empresas familiares buscam caminhos para a profissionalização conforme aponta Floriane(2007). Para o autor a "liderança e profissionalização parecem ser, assim, os pontos nevrálgicos da estrutura da empresa familiar, no sentido de dar-lhe perspectiva de prosperar [...]" (FLORIANE, 2007, p.224)

Bornholdt (2005) destaca que a gestão de empresas familiares demanda competência para lidar com a complexidade das relações afetivas e financeiras. Um dos pontos centrais destacado pelo referido autor é a necessidade de se conhecer profundamente a cultura organizacional da empresa familiar. Bernholdt (2005) destaca ainda que a cultura da família empresária norteia o modo de governar a empresa e pode ser ponto de conflito, que se estabelece entre a objetividade requerida na administração da empresa e os sentimentos de cada familiar envolvido na gestão da empresa familiar.

Nas empresas familiares existe uma maior complexidade da gestão, pois há o envolvimento emocional dos membros da família que constituem a gerência. Vista disso, podem ocorrem situações em que a estabilidades das relações familiares será atingida pelas divergências decorrentes das ações desenvolvidas no trabalho (HATAK et al. 2016).

Os conflitos muitas vezes surgem por questões relacionadas com o comportamento das pessoas envolvidas na administração da empresa Martinelli e Almeida(1998). Posto isto, é papel do gestor empreendedor é saber articular para lidar com os mais variados tipos de interesses, de pressões e de cobranças, pois aspectos familiares não podem interferir no bom andamento da gestão da empresa. (OLIVEIRA, 2009),

Segundo Morgan (2006), o poder autoritário costuma ser presentes nas chamadas organizações paternalistas, nas quais o poder absoluto encontra-se nas mãos de um indivíduo ou de grupos pequenos. Nesse modelo de gestão, o chefe, por ser o grande influenciador, domina toda a organização, determinando quais serão seus objetivos e sendo o principal agente no que tange à tomada de decisão (GUIMARÃES, 2007).

Segundo Bernhoeft (2001) um dos graves erros que continua sendo cometido no tratamento das empresas familiares no Brasil é não fazer uma clara separação entre controle e gestão.

Uma adequada gestão administrativa deve partir dos quatro princípios da administração: planejar, organizar, executar e controlar, segundo Floriani (2007) isto faz parte de elementos básicos que precisam ser trabalhados e desenvolvidos por parte do administrador, isto vale para empresas familiares também.

\section{Procedimentos metodológicos}

A pesquisa pode ser classificada como qualitativa quanto à abordagem, descritiva quanto aos objetivos e estudo de caso quanto aos procedimentos.

A pesquisa qualitativa valoriza o estudo e a análise do campo empírico no ambiente no qual o fenômeno estudado ocorre, pois um fenômeno é melhor compreendido quando observado no contexto em que ocorre (GODOY 1995). A pesquisa descritiva por sua vez permite ao pesquisador expor as características singulares de determinado fenômeno conforme salienta Vergada (2000).

$\mathrm{Na}$ pesquisa qualitativa descritiva o ambiente e as pessoas devem ser olhados holisticamente de forma que a perspectiva do participante da pesquisa seja considerada (GODOY, 1995). Adotando-se a pesquisa qualitativa descritiva como opção metodológica, o trabalho foi desenvolvido, inicialmente, com base em uma pesquisa bibliográfica sobre a gestão de empresas familiares ancorados em Marconi e Lakatos (2010). A pesquisa bibliográfica proporcionou condições para o embasamento teórico e a compreensão do problema de pesquisa.

Quanto aos procedimentos metodológicos a pesquisa pode ser classificada como um estudo de caso. O estudo de caso permite não só o contato do pesquisador com o fato como também permite uma compreensão maior da realidade estudada (YIN, 2001). Nessa perspectiva, buscou-se compreender como é a gestão da empresa familiar Savana Serviços na perspectiva dos gestores. 
Para a coleta de dados da realidade estudada - a empresa Savana Serviços - foram realizadas entrevistas com a sócia e gestora da empresa e uma funcionária que atua no setor administrativo. Além disso, no processo de coleta dos dados considerou-se a observação da autora, que realizou estágio na empresa. Entrevistas e observação participante são consideradas por Yin (2001) como formas adequadas de coleta de dados para estudos desta natureza. Cabe ressaltar que após a análise dos dados as entrevistadas foram acionadas para sanar dúvidas e explicar questões que não estavam claras para a pesquisadora.

A análise dos resultados foi inspirada na análise de conteúdo proposta por Bardin (2011). O foco da análise foi compreender o processo de gestão da Empresa Savana Serviços a partir da perspectiva dos familiares. Não foram adotadas todas as etapas da análise de conteúdo pelo fato do trabalho focar apenas na gestora herdeira do fundador.

Como característica do estudo de caso, os resultados apresentados neste trabalho referem-se apenas à empresa Savana Serviços. As conclusões obtidas são delimitadas a esta empresa, não podendo, portanto, ser generalizadas para todas as empresas do ramo, conforme salienta Gil (2010).

\section{Apresentação e análise dos resultados}

\section{Savana Serviços: a trajetória de uma empresa familiar de Araxá, Minas Gerais}

A história da Empresa Savana iniciou-se em 1997 quando foi fundada pelo Sr. Adão que à época da fundação saiu de um empreendimento familiar para montar seu próprio negócio criando a Empresa Moura Soluções. Anteriormente ele havia investido por vinte anos no ramo de marcenaria e madeira juntamente com seus irmãos e pai em uma empresa chamada Moura Irmãos. De acordo com o depoimento da Márcia, filha do Sr. Adão, “após o falecimento do meu avó, em 1986, os herdeiros continuaram a marcenaria. Em 1997 meu pai saiu da empresa e começou uma nova empresa. Ele deixou tudo que havia investido para traz, todo seu acerto da empresa que trabalhava antes de montarem a sociedade". O fim da sociedade familiar se deu devido à insatisfação do Sr. Adão da forma como os irmãos gerenciavam a empresa. Assim, ele buscou iniciar uma vida independente e empreender da maneira que considerava correta abrindo a empresa Moura Soluções que atualmente se chama Savana Serviços.

A Moura Soluções prestava serviços de poda e limpeza diária da área verde na Companhia Brasileira de Metalúrgica e Mineração (CBMM), que atua na exploração do nióbio em Araxá. Além da limpeza diária da área verde, a Moura Soluções realizava a derrubada das árvores, de acordo com a demanda da CBMM, em troca da madeira e da lenha, que eram comercializadas pelo Sr. Adão. Este tipo de serviço gerou a demanda para a aquisição de um caminhão e de uma máquina para desfiar tora. A entrevistada destaca que "este investimento aumentou a receita da empresa e a partir daí com muita garra e determinação meu pai iniciou sozinho o negócio e foi expandindo".

Para aumentar a receita do negócio e viabilizar o pagamento do investimento realizado, o Sr. Adão procurou um cliente que precisava desmatar uma área para explorar o minério e propôs desmatar em troca do material lenhoso gerado do corte e começou a comercializar. De acordo com sua filha este serviço viabilizou "o levantamento de capital para pagar os equipamentos, as motosserras e o caminhão que ele havia comprado e parcelado". No início ela destaca que o pai "dirigia o caminhão e operava a derrubada de árvores" e contava com três funcionários para carregar o caminhão com a madeira e realizar a entrega para o cliente.

Após seis meses de existência da Moura Soluções, a filha Márcia Fortunato começa a trabalhar na empresa na área administrativa. Após a percepção de que o mercado de lenha tinha desaquecido, a Moura Soluções passa a atuar como carvoeira também. O mercado estava mais propício à venda de carvão do que para a venda de lenha. A carvoeira foi mantida por 4 anos e com boa rentabilidade no início. Em função das crises das siderúrgicas, principal cliente, a carvoeira foi desativada em 2009.

A mudança do cenário no mercado levou pai e filha a repensar novos nichos de atuação para a empresa. Com o espaço já alugado na época decidiram montar uma marcenaria pela sinergia do negócio com os empreendimentos que atuavam até então. A partir daí a Moura Soluções começa a 
atuar na marcenaria com MDF, além da madeira. Nessa mesma época, a empresa CBMM passou a necessitar dos serviços de jardinagem, combate ao cupim, limpeza de barragem, e como já conhecia os serviços prestados pelo Sr. Adão propôs que ele atendesse esta demanda.

A oportunidade gerada pela demanda da CBMM cria uma nova área de atuação para a Moura Soluções: prestação de serviços de jardinagem e afins. Simultaneamente ao período de crescimento e expansão da área de atuação da empresa, Márcia se casa em 2004 e seu esposo torna-se sócio da empresa em 2012. Fernando passa a responder pela locação de bens como caminhão e containers e similares, uma nova área de atuação da Moura Soluções.

Além da atuação do Fernando na locação de bens, a empresa conta com a participação da Márcia na área comercial e administrativa. O Sr. Adão acompanha o processo produtivo na marcenaria e tem conhecimento de tudo que acontece na empresa.

De acordo com a Márcia, "a sociedade se consolidou de lá para cá e deu certo. Os negócios cresceram, gerando lucros e prosperidade". Ela destaca ainda que a empresa "sempre primou pela busca da excelência através da oferta de novos serviços e pela capacidade do pai de aceitar novos desafios".

Márcia destaca que tanto ela quanto o pai sempre cobraram dos funcionários um comprometimento com os valores da empresa. Segundo ela, os valores são "trabalho, honestidade e dedicação". Márcia destaca também que "o comprometimento da equipe garante o sucesso e crescimento da empresa [...]". A gestora afirmou que "o crescimento sustentável [da empresa] é baseado na solidez financeira da empresa e demanda controles eficientes e sistemas de informação eficazes". No entanto, a gestora não exemplificou como a solidez financeira da empresa é mensurada e não disponibilizou dados para aferir esta afirmativa. Na percepção da gestora a empresa apresenta um crescimento sustentável e solidez financeira. Destaca-se também que nem a gestora nem a funcionária entrevistada apresentaram como é o sistema de controle da empresa.

De acordo com as entrevistas há uma auto-percepção de que a empresa investe nos seus colaboradores para que desenvolvam capacidade de liderança agregando novos valores e os objetivos da empresa; que estejam satisfeitos com as atividades que exercem; que participem ativamente das decisões do negócio e que tenham uma conduta ética e de total transparência no relacionamento com clientes e fornecedores. Vale destacar que dentre estes funcionários estão também incluídos os membros da família. Destaca-se que a gestora não exemplificou ou detalhou ações ou histórias quando indagada sobre como o potencial de liderança é desenvolvido e se realmente há espaço para a participação dos funcionários no processo de tomada de decisão. Na observação participante foi possível verificar que os funcionários mais antigos têm prestígio com os proprietários e são ouvidos antes de decisões sobre material a ser comprado e qualidade de um ou outro fornecedor. No entanto, a decisão final sempre é do pai ou filha.

Os primeiros anos da empresa são marcados pela ausência de capital e pela adoção de uma estrutura humana enxuta. Contudo, o crescimento dos negócios e a variação nas áreas de atuação permitiram a realização de novos investimentos. No início a escolha de uma nova área de atuação foi baseada na visão do senhor Adão sobre as possibilidades de rentabilidade que aquela área poderia gerar. Além da vontade pessoal de crescimento da empresa, senhor Adão não tinha receio dos desafios e enxergava oportunidade de negócio em toda demanda que tomava conhecimento. Em 2019 a empresa atua na prestação de serviços, na venda e locação. No caso específico de locação, a empresa disponibiliza para os clientes a locação de caminhão, caminhão guindaste, caminhão moquém, containers.

Sr Adão situa que resolveu trocar o nome de Moura Soluções para Savana Serviços em 2011 para se desvincular da antiga empresa que seus irmãos tinham. Já no ano de 2014, a empresa passou a investir no ramo de extintores de incêndio com capital retirado da Savana.

A Savana passa a ser detentora de 50\% de uma loja de extintores. A aquisição de parte desta empresa é explicada pela demanda de clientes, que foi analisada como oportunidade de atuação em novo ramo. Márcia afirmou que muitos clientes da Savana relatavam a demanda pelo serviço e a carência do mercado em Araxá: "muitos clientes pediram para a Savana atuar na prestação de serviço de manutenção, reparo e recarga de extintores. Como não tínhamos experiência, procuramos uma empresa que oferecia este serviço em Araxá e a empresa estava praticamente falida". Tanto Márcia 
quanto o pai enxergaram uma oportunidade de negócio. Sem nenhuma análise de mercado ou plano de negócios decidiram adquirir 50\% da empresa de extintores e passaram a encaminhar os clientes da Savana, que demandavam este serviço, para o novo empreendimento. Nas suas palavras: "demos um up na empresa e levamos nossos clientes para lá [...] A gestão e o controle da empresa é de responsabilidade dos nossos sócios. Mas eu faço uma vistoria mensal na empresa". No novo empreendimento além da mudança no layout da loja houve melhorias na estrutura física e na aquisição de novas máquinas, que aumentaram a eficiência e qualidade do serviço prestado, os novos sócios exigiram também a implantação de um sistema de gestão chamado SPK, que também é usado na Savana.

A empresa, ao longo de sua história, passou por algumas mudanças e por situações complicadas, mas hoje é uma empresa sólida com mais de 22 anos no mercado. Por estratégia tributária, a empresa abriu um novo C.N.P.J. com efeitos sobre a tributação. A sede da marcenaria é própria e em local próximo está sendo construído o escritório, onde funcionará a parte administrativa da Savana Serviços. Além disso, a empresa possui máquinas e veículos que demonstram sua capacidade de atendimento da demanda: 3 empilhadeiras, 5 caminhões e 11 carros auxiliares.

Percebe-se na trajetória da Savana a influência positiva do empreendedorismo do Senhor Adão e a importância da atuação da Márcia no processo de gestão. No entanto, Márcia destaca que a equipe da empresa tem peso no sucesso. Ela relata que "a maioria dos funcionários está na nossa empresa a quase 19 anos [...]. Eles começaram a trabalhar aqui sem experiência e conhecimento no mercado". A baixa rotatividade e o tempo médio alto de empresa contribuem para relações sociais saudáveis e um nível de confiança na equipe que a gestora considera como diferencial. Márcia afirma que "[...] há um ótimo convívio entre a gestão e os funcionários, por cada um respeitar a parte que toma conta, problemas e discussões tem, mas é mais tranquilo [...]." Para ela, o fato da empresa investir em uma área de lazer é prova da preocupação da gestão com os funcionários, além de ser um espaço propício para melhorar as relações entre os membros da equipe e entre as equipes e os proprietários.

Tanto a decisão sobre em quais negócios atuar com a área de convivência são consideradas pela gestora como provas da preocupação com as pessoas na empresa. Márcia destacou que "a extinção da carvoeira foi uma decisão em conjunto" e o investimento em "uma área de lazer para estar sempre juntos" podem ser considerados como decisões que afetaram positivamente a qualidade de vida dos trabalhadores e gestores da Savana.

Apesar de destacar as relações sociais na Savana, Márcia percebe a necessidade de aumentar a equipe que atua na área administrativa para aprimorar os controles. Segundo ela destacou "precisamos de mais funcionários na área do escritório para ter um controle mais certo da área de segurança dos funcionários e um controle maior de tarefas cumpridas e prazos". Em maio de 2019 a empresa contava com a Márcia e mais uma funcionária, além da estagiária, para realizar todo o trabalho administrativo da Savana. Este trabalho envolve o controle de funcionários, a contratação de novos funcionários, quando necessária, a análise de novas propostas de prestação de serviços, o processo de compras que envolve cotação, compra e conferência. Márcia afirmou que "[...] estou vendo a necessidade de mais funcionários e com isso [a contratação] farei uma distribuição de serviços tendo assim um resultado com mais excelência em todas as áreas que tenho notado certa perda de qualidade".

Esta demanda de aumento da equipe também pode ser explicada pela oportunidade de expansão da área de atuação. Márcia relatou que "[...] já estamos com projetos de começar uma obra em Catalão em locações de bens e prestação de serviços de mão de obra na parte de jardinagem e impermeabilização de barragem". A expansão em áreas que já possuem know how visa o aumento da eficiência e o crescimento da empresa com sinergia.

O crescimento é visto como estratégia para evitar a acomodação e a perda de espaço para possíveis concorrentes. Ademais, o crescimento reduz a dependência da empresa em relação à carta de clientes atuais. A marcenaria é outra área que a Savana investe em crescimento da capacidade produtiva. Há também a intenção de iniciar a atuação na oferta de móveis planejados.

Nesta nova fase de crescimento fica claro que a estratégia é expandir a região geográfica de atuação com foco em uma área de domínio como prestação de serviços para mineradoras e marcenaria. 
Considerando que o senhor Adão possui educação formal até a $5^{a}$ série e que Márcia é formada em psicopedagogia pode-se afirmar que a vivência no dia a dia da gestão da Savana permitiu aos proprietários, que possuem vínculos familiares, a desenvolver competências fundamentais para a administração, manutenção e crescimento da empresa.

Esta trajetória de expansão na empresa familiar analisada bem como a evolução dos negócios se deu devido às forças que estimularam o crescimento da empresa, delimitadas por Gersick et al (1997). Estas 'forças que puxam' os negócios familiares se referem às condições econômicas e ambientais que tornam atraentes e determinantes para a abertura de novos empreendimentos. No caso específico da Savana Serviços a força que impulsionou a abertura da primeira empresa foi o descontentamento do gestor fundador da empresa com o negócio familiar deixado por seu pai, que era gerenciado por ele em sociedade com os irmãos. A insatisfação com a forma como o negócio herdado era conduzido pela segunda geração levou o Senhor Adão a empreender na busca pelo seu próprio investimento e evitar um conflito familiar.

Outra força que impulsionou foi a percepção das demandas de mercado, mesmo sem pesquisas estruturadas. A demanda da empresa CBMM por serviços para limpeza e derrubada da vegetação na área destinada à mineração caracteriza-se como uma oportunidade que foi sabiamente aproveitada pelo Senhor Adão. A empresa passou a contar com novos processos produtivos, mas ainda não havia um sistema de gestão determinado até a entrada da filha do fundador na empresa. Apesar da saída do Senhor Adão da empresa familiar herdada, a experiência adquirida e a percepção de oportunidades foram o pontapé inicial para ele investir no seu próprio negócio.

A entrada da filha e do genro na Empresa Familiar Savana Serviços alterou a estrutura administrativa e os papeis passaram a ser mais delimitados na empresa. O Senhor Adão é responsável pela produção na marcenaria, a Márcia assume as relações com clientes e realização de orçamentos, o Fernando é responsável pela locação de maquinários. A descentralização permitiu um crescimento mais sólido da empresa, mas ainda percebe-se a necessidade de melhores controles.

Para delimitar de forma mais clara a trajetória da empresa, destaca-se as fases desde a fundação até 2019:

\begin{tabular}{|l|l|}
\hline \multicolumn{1}{|c|}{ FASES HISTÓRICAS } & PERÍODO \\
\hline Fundação - Empresa Moura Soluções. & $1997-2009$ \\
\hline Moura Soluções - Carvoeira & $2005-2009$ \\
\hline Moura Soluções - Locações & $2009-2012$ \\
\hline Savana Soluções - Prestação de Serviços - Venda e Locação. & 2012 - 2019 \\
\hline
\end{tabular}

O intuito maior foi demonstrar cada uma destas fases, buscando interpretá-las e as características que marcaram cada etapa da história da empresa Savana Serviços.

Transformando desafios em oportunidades de negócio: a gestão familiar na trajetória da Empresa Savana Serviços

A empresa começou com uma estrutura humana enxuta e em 2019 possui 53 funcionários atuando em diferentes atividades como marcenaria, locações de bens e prestação de serviços.

A trajetória da empresa como descrita no item anterior comprova como os desafios foram transformados em oportunidades de negócio: a exclusão da carvoeira abriu espaço para a atuação da empresa em atividades mais rentáveis. A entrada do genro do senhor Adão no negócio também é considerada um marco na diversificação do negócio.

A inauguração da sede própria da empresa (escritório) acontecerá em 2020 com uma estrutura física mais adequada em departamentos e salas separadas, criando condições mais adequadas para o 
crescimento e gestão da Savana Serviços.

Apesar da evolução do negócio, a gestão da empresa carrega os vícios de uma gestão familiar que não documenta e formaliza as atividades. Márcia afirmou que "ainda não consegui mapear processos na empresa”. A justificativa está na necessidade de mais funcionários para atuarem na área administrativa. Segundo ela: "[...] agregando mais funcionários na área administrativa pretendo mapear mais as falhas e tentar corrigi-las". Ainda, segundo a Márcia, um reforço de força de trabalho no escritório permitirá um "[...] aproveitamento melhor do tempo: trabalhar mais com planejamento; pesquisar mais; definir a estrutura organizacional, organizar os processos administrativos, operacionais e financeiros; integrar mais a equipe e elaborar objetivos, metas e missão; atribuir responsabilidades aos colaboradores e avaliar periodicamente a produtividade e o desempenho da equipe".

O discurso da Márcia reforça que a gestão é feita com base na experiência dos proprietários. A profissionalização da gestão ainda está no discurso e ancorada na demanda de mais funcionários. No entanto, não há nenhuma intenção clara de contratação de uma consultoria ou de um administrador para auxiliar na adequação do processo de gestão da empresa às necessidades do estágio de evolução que se encontra a empresa.

De acordo com informações obtidas pela entrevista com a assistente administrativa que trabalha na Savana Serviços "a gestão da empresa é dividida em setores". Ainda nesta entrevista, a assistente administrativa informou que "[...] para facilitar no dia a dia da empresa todas as documentações (Notas Fiscais - Entrada/Saída, boletos, documentos de funcionários, documentos de segurança.) são lançadas em programas onde se tem fácil acesso sempre que necessário”. O uso de softwares auxilia no compartilhamento das informações, mas destaca que "as decisões ainda são centralizadas no senhor Adão e na Márcia”.

Como a Savana Serviços está em contato direto com clientes de diferentes serviços a divisão em setores é fundamental para facilitar a realização de orçamentos, produção, entrega e análise de faturamento. A assistente administrativa afirma que "[...] como atendemos em vários segmentos, temos setores divididos para facilitar o desenvolvimento no atendimento". Ela detalhou o processo de atendimento ao cliente na marcenaria, mostrando conhecimento das atividades nas diferentes áreas de atuação da Savana Serviços: "[na marcenaria] existe um controle de produção desde o atendimento onde é realizada uma ordem de serviço, logo após é passado aos marceneiros para produção. Tudo é sempre acompanhado para verificação de qualidade e assim que o produto estiver pronto é realizada a entrega. Na marcenaria trabalhamos com a produção puxada, que é de acordo com a demanda. Compras de materiais são efetuadas após o fechamento do serviço porque não trabalharmos com grandes estoques que ocasionam dinheiro parado". A assistente administrativa ainda ressalta a preocupação da gestão com a comunicação: "quanto ao setor pessoal temos atualmente 53 funcionários que semanalmente realizam treinamentos de segurança, e mensalmente reuniões para melhor comunicação entre empresa e funcionário".

A gestão da empresa está nas mãos de pai e filha que possuem uma vasta experiência do negócio da empresa, pois atuam na atividade há praticamente 29 anos. O genro também tem poder de decisão e é apresentado como sócio do empreendimento. Os colaboradores da Savana Serviços têm funções definidas dentro da especialização ou área de atuação de cada um.

As decisões na Savana Serviços são compartilhadas entre membros da família e muitas vezes são tomadas em reuniões familiares. A mistura família/negócio é comum em empreendimentos familiares. Apesar da percepção da necessidade de melhorar procedimentos e profissionalizar o processo de tomada de decisão, a ação para mudar a realidade da gestão da empresa ainda é distante.

Em termos de rotinas administrativas e operacionais a responsabilidade geral fica a cargo da assistente administrativa, que é formada em Engenharia de Produção e está há cinco anos na empresa. A assistente administrativa está sob a supervisão da Márcia e hierarquicamente subordinada aos proprietários. A concentração administrativa em uma única funcionária é considerada um gargalo da gestão da empresa. Apesar da demanda por força de trabalho estar presente no discurso da gestora não houve percepção de mudança de cenário no curto prazo.

A experiência do Senhor Adão no setor de madeiras vem de muitos anos e da própria vivência 
profissional na empresa de seu pai. De maneira informal, pode afirmar que o senhor Adão assume as responsabilidades de um gerente de produção e operações na marcenaria. No entanto, não há um organograma delimitando funções e responsabilidades na Savana Serviços. A estrutura organizacional é simples e informal.

A trajetória da empresa Savana demonstra que a atuação em outros mercados e áreas foi uma alternativa para crescimento e consolidação. A abertura do Senhor Adão para novos métodos de trabalho (locação, venda e serviços), entrada de novo sócio (Fernando, que é genro) e a aceitação da filha na gestão do empreendimento lançaram a empresa na trilha do desenvolvimento.

A Savana Serviços é uma empresa familiar conforme descrito por Déry et al (1993). Ou seja, a família possui propriedade total da empresa e assume a gestão no dia a dia e as decisões estratégicas de investimento.

As rotinas da empresa ainda não eram claramente formalizadas, a estrutura hierárquica era simples, quanto à comunicação a informação era repassava pelo fundador aos demais. A estratégia nessa fase não era sistematizada e é repassada pelo gestor fundador aos seus poucos colaboradores. No entanto, o tipo de visão era empreendedora, o que pode ser confirmado pelos inúmeros serviços prestados em empresas do porte da Companhia Brasileira de Metalurgia e Mineração.

A empresa enfrentou uma série de obstáculos nessa época. O maior deles a falta de equipamentos e realização de serviços em troca de madeira, a aquisição do caminhão. A falta de sistematização e formulação estratégica foi um dos motivos que levou a empresa na fase inicial a diversificar suas áreas de negócio e enfrentar significativos problemas financeiros. A situação foi resolvida com o redirecionamento negocial da empresa com a entrada da filha como sócia gestora. Essa primeira fase influenciou a história da empresa, pois lançou as bases para três aspectos centrais na empresa: a família, a estratégia e os valores básicos de gerenciamento e administração.

\section{Considerações finais}

A pesquisa na empresa Savana Serviços comprovou a importância do papel do fundador na empresa familiar. No caso desta empresa, o fundador foi peça-chave para a evolução do empreendimento. As decisões de atuação em novos negócios - prestação de serviços e locação de equipamentos, por exemplo - têm a participação direta do fundador com o apoio dos outros membros da família que estão atualmente na gestão da empresa.

A gestão da empresa Savana Serviços é compartilhada entre pai, filha e genro. Apesar da empresa não possuir um organograma formal há uma departamentalização simples com uma divisão informal de responsabilidades, o que facilita a tomada de decisão referente a cada negócio ou setor.

A trajetória da empresa Savana Serviços, descrita no trabalho, comprova o espírito empreendedor do fundador, que assumiu novos negócios mesmo sem capital e permitiu o crescimento da empresa. A empresa começa a atuar na prestação de serviços de poda e limpeza diária na área verde da CBMM como Moura Soluções. O atendimento a este cliente gerou oportunidade de negócio e a empresa passa a operar como carvoeira, atividade na qual atuou até 2009. Uma década depois, nova oportunidade de negócio surge e a Moura Soluções passa a locar maquinários, além de marcenaria com MDF e madeira. Em 2012 a empresa é denominada Savana Serviços com atuação em diferentes negócios.

$\mathrm{Na}$ trajetória da empresa a filha do fundador e o genro são incorporados como sócios e passam a atuar diretamente na gestão do empreendimento. A empresa possui um processo de tomada de decisão centralizado no fundador e familiares que participam da gestão. Apesar de destacarem a abertura para os funcionários, a decisão é centralizada nos proprietários.

A falta de informação padronizada na Savana Serviços, o que é comum em empresas familiares, caracteriza-se como uma limitação da pesquisa, pois a discussão dos resultados fica limitada na análise do discurso dos entrevistados. Neste sentido, sugere-se como agenda de pesquisa a investigação em duas ou mais empresas familiares que atuam no mesmo setor para uma análise comparativa. 


\section{Referências}

BARDIN, L. Análise de conteúdo. São Paulo: Edições 70. 2011.

BERNHOEFT, Renato, 1942-Empresa Familiar: Sucessão profissionalizada ou sobrevivência Comprometida/Renato Bernhoeft. _ 3 ed. São Paulo: Nobel, 2001.

BERNHOEFT, Renato; GALLO; Miguel. Governança na Empresa Familiar: gestão, poder e sucessão. 4. ed. Rio de Janeiro, RJ: Elsevier, 2003. 148 p.

BORNHOLDT, Werner. Governança na empresa familiar: implementação e prática. Porto Alegre: Bookman, 2005. BERNHOEFT, Renato. Empresa familiar: sucessão profissionalizada ou sobrevivência comprometida. São Paulo: Novel, 1989.

CASILLAS, José Carlos; VÁZQUEZ, Adolfo; DÍAZ, Carmen. Gestão da empresa familiar: conceitos, casos e solução. São Paulo: Thomson Learning, 2007.

DAVIS, J. A. The influence of life-stage on father-son work relationship in family companies. Unpublished doctoral dissertation. Harvard Business School, 1983.

DÉRY, Richard et al. La Varieté des Entreprises Familiales: Construction Théorique et Typologique. Montréal: Cahier de Recherche no. GREF 93-08 Décembre, 1993 p. 1-25

FREZATTI, Fábio. Orçamento empresarial: planejamento e controle empresarial. 6.Ed. São Paulo: Atlas, 2015.

FREZATTI, Fábio et al. Estágios de ciclo de vida e perfil de empresas familiares brasileiras. Rev. adm. empres., São Paulo, v. 57, n. 6, p. 601-619, Dec. 2017 . Disponível em: $<$ http://www.scielo.br/scielo.php?script=sci_arttext\&pid=S0034-

75902017000600601\&lng=en\&nrm=iso $>$. Acesso em 16 de junho de 2019. http://dx.doi.org/10.1590/s0034-759020170607.

FLORIANI, Oldoni Pedro. Empresa familiar ou... inferno familiar? 2. ed. Curitiba: Juruá, 2007.

GERSICK, Kelin E. De geração para geração: ciclos de vida da empresa familiar. São Paulo: Negócio, 2017.

GERSICK, Kelin E. et al. De geração para geração: ciclo de vida das empresas familiares. 2. ed. São Paulo: Negócio, 1997.

GIL, Antonio Carlos. Como elaborar projetos de pesquisa. 5. ed. São Paulo: Atlas, 2010. 184p.

GODOY, Arilda Schmidt. Introdução à pesquisa qualitativa e suas possibilidades. Revista de Administração de Empresas. São Paulo, v.35, n.2, p.57-63. 1995. Disponível em: <http://www.scielo.br/pdf/rae/v35n2/a08v35n2.pdf>. Acesso em: 26 de junho de 2019.

GUIMARÃES, V. da F. Bases de poder do supervisor, conflitos intragrupais e comprometimento organizacional e com a equipe: um estudo exploratório, 2007. 143fls. Dissertação (Mestrado em Psicologia Aplicada), Universidade Federal de Uberlândia, Uberlândia, 2007.

HATAK, Isabella; KAUTONEM, Teemu; FINK, Matthias; KANSIKAS, Juha. Innovativeness and family-firm performance: The moderating effect of family commitment. Technological forecasting 
and social change, v. 102, p. 120-131, 2016.

LODI, João Bosco. A empresa familiar. 5 ed. São Paulo: Pioneira, 1998.

LODI, João Bosco. A Ética na Empresa Familiar. São Paulo: Pioneira, 2014.

MARCONI, M. de A.; LAKATOS, E. M. Fundamentos de metodologia científica. 7. ed. Editora Atlas, 2010.

MARTINELLI, D. P.; ALMEIDA, A. P. de. Negociação e solução de conflitos. São Paulo: Atlas, 1998.

MARTINS, Ives Gandra da Silva; MENEZES, Paulo Lucena de; BERNHOEFT. Empresas familiares brasileiras: perfil e perspectivas. São Paulo: Negócio Editora, 1999.

MURITIBA, S. N.; MURITIBA, P. M.; DOMINGUES, L. M.; DIO, G.; ZAVARIZZI, F. Governança Corporativa e Sucessão em Empresas Familiares. Revista de Carreiras e Pessoas, v. 6, n. 3, p. 346357, 2016.

OLIVEIRA, Djalma de Pinho Rebouças de. Empresa familiar: como fortalecer o empreendimento e otimizar o processo sucessório. 2. ed. São Paulo: Atlas, 2006.

OLIVEIRA, Luís Martins de; PEREZ JÚNIOR, José Hernandez; SILVA, Carlos Alberto dos Santos. Controladoria estratégica. São Paulo: Atlas, 2002.

PAIVA, K. C. M. de, OLIVEIRA, M. C. de S. M. de, \& Melo, M. C. de O. L. (2008). Produção científica brasileira sobre empresa familiar - um metaestudo de artigos publicados em anais de eventos da ANPADno período de 1997-2007. RAM-Revista de Administração Mackenzie, 9(6), 148-173. doi:10.1590/S1678-69712008000600008

SEBRAE. Artigos sobre empresas familiares. Disponível em:

<https://www.sebrae.com.br/sites/PortalSebrae/Busca?q=Empresa \%20familiar $>$ SEBRAE:

Serviço Brasileiro de Apoio às Micro e Pequenas Empresas. 2019.

TESTON, Sayonara de Fátima; FILIPPIM, Eliane Salete. Perspectivas e Desafios da Preparação de Sucessores para Empresas Familiares. Rev. adm. contemp. Curitiba , v. 20, n. 5, p. 524545, Oct. 2016.

YIN, R. K. Estudo de caso: planejamento e métodos. 2. ed. Porto Alegre: Bookman, 2001. 